Background: Baricitinib (BARI), an oral, selective Janus kinase (JAK) 1 and JAK2 inhibitor, improved disease severity in adults with systemic lupus erythematosus (SLE) receiving standard background therapy in a phase 2 trial $^{1}$. There were no meaningful reductions in least squares mean change from baseline (BL) in levels of serologic biomarkers for SLE with BARI treatment, including anti-double-stranded deoxyribonucleic acid (anti-dsDNA) antibodies and complement component $(\mathrm{C}) 3$ and $\mathrm{C} 4{ }^{1}$.

Objectives: Evaluate the median change from $\mathrm{BL}$ in serologic biomarkers in subgroups and the overall population of BARI-treated SLE patients, in addition to the Systemic Lupus Erythematosus Responder Index-4 (SRI-4) response by normalization of anti-dsDNA.

Methods: Data were assessed from the phase 2 trial JAHH (NCT02708095). The median change from $\mathrm{BL}$ in anti-dsDNA, IgG, C3, and C4 was evaluated over time among the following populations at $\mathrm{BL}$ : anti-dsDNA positive ( $\geq 30 \mathrm{IU} / \mathrm{mL}$ ), low C3 ( $<90 \mathrm{mg} / \mathrm{dL})$, low C4 $(<10 \mathrm{mg} / \mathrm{dL})$, and all patients for IgG. Statistical tests were conducted for BARI 2-mg and 4-mg compared with placebo (PBO). Among patients who were anti-dsDNA positive at $\mathrm{BL}, \mathrm{SRI}-4$ responder rate was compared for those who stayed positive or achieved normal levels by Week (Wk) 24. Results: Among patients who were anti-dsDNA positive at $\mathrm{BL}$, significant decreases of anti-dsDNA antibodies were observed for BARI 2-mg and 4-mg compared to PBO beginning at Wks 2 and 4, respectively, and continuing through Wk 24 (Figure 1 and Table 1). Moreover, reductions of IgG levels were found for BARItreated patients including significant decreases for BARI 4-mg compared to PBO at Wks 12 and 24 (Table 1). Among patients who had low levels of C3 and C4 at $\mathrm{BL}$, no significant differences in median change from $\mathrm{BL}$ were observed over time with BARI compared to $\mathrm{PBO}$. For patients who were anti-dsDNA positive at $\mathrm{BL}$, no relationship in SRI-4 responder rate was observed for those who stayed positive or achieved normal levels by Wk 24, possibly due to the limited sample size.

Conclusion: BARI treatment resulted in a rapid and sustained significant decrease in anti-dsDNA antibodies compared to PBO among anti-dsDNA positive SLE patients at BL, as well as a significant decrease in IgG levels in the 4-mg group at Wks 12 and 24. These data suggest that BARI may have an effect on B cell activity in SLE.

REFERENCES:

[1] Wallace D et al. Lancet. 2018;392:222-231.

Table 1.

\begin{tabular}{|c|c|c|c|c|c|c|c|c|c|}
\hline \multirow[b]{2}{*}{ Week } & \multicolumn{3}{|l|}{ РBO } & \multicolumn{3}{|c|}{ BARI 2-mg } & \multicolumn{3}{|c|}{ BARI 4-mg } \\
\hline & 4 & 12 & 24 & 4 & 12 & 24 & 4 & 12 & 24 \\
\hline $\begin{array}{l}\text { Anti- } \\
\text { dsDNA } \\
(I U / m L)^{a} \\
\text { IgG }(g / L)^{b}\end{array}$ & $\begin{array}{l}0.2(-17.2 \\
17.3) \\
-0.31\end{array}$ & $\begin{array}{l}2.6 \\
(-14.8, \\
18.4) \\
0.09\end{array}$ & $\begin{array}{l}3.0 \\
3,(-14.9 \\
28.3) \\
-0.04\end{array}$ & $\begin{array}{l}-15.4^{\star \star} \\
,(-31.4 \\
1.9) \\
-0.60\end{array}$ & $\begin{array}{l}-18.1^{*} \\
(-42.0 \\
4.1) \\
-0.30\end{array}$ & $\begin{array}{l}-29.6^{\star \star} \\
(-55.1 \\
10.3) \\
-0.51\end{array}$ & $\begin{array}{l}-17.9^{\star \star} \\
(-42.7 \\
1.8) \\
-0.56\end{array}$ & $\begin{array}{l}-23.3^{\star \star \star} \\
(-50.9 \\
-5.9) \\
-0.65^{\star \star}\end{array}$ & $\begin{array}{l}-15.1^{\star \star} \\
(-71.9 \\
-4.6) \\
-0.60^{\star \star}\end{array}$ \\
\hline & $\begin{array}{l}(-1.1 \\
0.4)\end{array}$ & $\begin{array}{l}(-1.1 \\
0.7)\end{array}$ & $\begin{array}{l}(-0.9, \\
0.9)\end{array}$ & $(-1.3,0.6)$ & $(-1.3,0.4)$ & $(-1.7,0.6)$ & $(-1.2,0.2$ & $(-1.3,0.2)$ & $(-1.7,0.2)$ \\
\hline
\end{tabular}

Data are median change from baseline $\left(25^{\text {th }}, 75^{\text {th }}\right.$ percentiles $) .{ }^{\text {a }}$ Data were assessed for patients that were anti-dsDNA positive $(\geq 30 \mathrm{IU} / \mathrm{mL}$ ) at baseline (PBO N=51, BARI 2-mg N=56, BARI 4-mg $\mathrm{N}=53$ ). ${ }^{\mathrm{b}}$ Data were assessed for all patients (PBO N=105, BARI 2-mg N=105, BARI 4-mg N=104). ${ }^{*} \mathrm{p} \leq 0.05,{ }^{* *} \mathrm{p} \leq 0.01,{ }^{* *} \mathrm{p} \leq 0.001$ for BARI vs. PBO.

Figure. Median change from baseline in anti-dsDNA (IU/mL) ${ }^{a}$

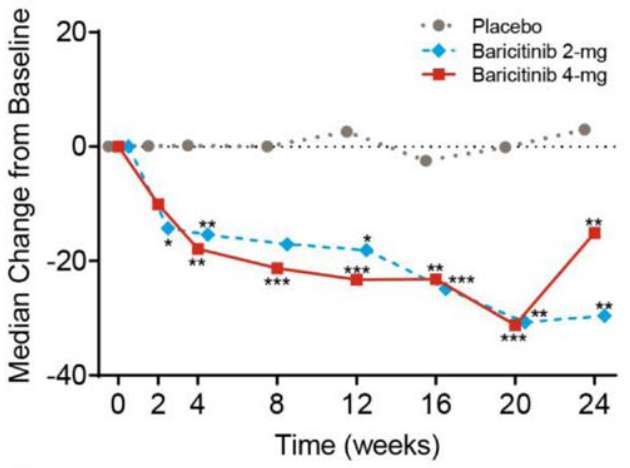

$\begin{array}{lllllllll}\text { Number of patients } & & & & & & & & \\ \text { Placebo } & 51 & 50 & 49 & 47 & 47 & 43 & 40 & 40 \\ \text { Baricitinib 2-mg } & 56 & 55 & 53 & 51 & 48 & 46 & 42 & 43 \\ \text { Baricitinib 4-mg } & 53 & 53 & 52 & 48 & 46 & 45 & 43 & 40\end{array}$

${ }^{a}$ Data were assessed for patients that were anti-dsDNA positive $(\geq 30 \mathrm{IU} / \mathrm{mL})$ at baseline. dsDNA=double-stranded deoxyribonucleic acid.

${ }^{*} p \leq 0.05,{ }^{* *} p \leq 0.01,{ }^{\star \star *} p \leq 0.001$ for baricitinib compared with placebo
Acknowledgements: The authors would like to acknowledge Nicole L. Byers, of Eli Lilly and Company, for medical writing and process support.

Disclosure of Interests: Thomas Dörner Speakers bureau: Eli Lilly and Company, Roche, and Samsung, Consultant of: AbbVie, Celgene, Eli Lilly and Company, Janssen, Novartis, Roche, Samsung, and UCB, Grant/research suppor from: Janssen, Novartis, Roche, Sanofi, and UCB, Ronald van Vollenhoven Consultant of: Abbvie, Biotest, BMS, Celgene, Crescendo, Eli Lilly and Company, GSK, Janssen, Merck, Novartis, Pfizer, Roche, UCB, and Vertex, Grant/research support from: Abbvie, Amgen, BMS, GSK, Pfizer, Roche, and UCB, Andrea Doria Speakers bureau: GSK, Janssen, Pfizer, and Roche, Consultant of: Celgene, El Lilly and Company, and GSK, Bochao Jia Shareholder of: Eli Lilly and Company, Employee of: Eli Lilly and Company, Damiano Fantini Shareholder of: Eli Lilly and Company, Employee of: Eli Lilly and Company, Jorge Ross Terres Shareholder of: Eli Lilly and Company, Employee of: Eli Lilly and Company, Maria Silk Shareholder of: Eli Lilly and Company, Employee of: Eli Lilly and Company, Stephanie de Bono Shareholder of: Eli Lilly and Company, Employee of: Eli Lilly and Com pany, Peter Fischer Shareholder of: Eli Lilly and Company, Employee of: Eli Lilly and Company, Daniel J. Wallace Consultant of: Amgen, Aurunia, Eli Lilly and Company, EMD Merck Serono, GSK, and Pfizer

DOI: 10.1136/annrheumdis-2021-eular.1015

\section{POS0687 A RANDOMISED DOSE RANGING, PLACEBO- CONTROLLED, PHASE II STUDY ASSESSING THE EFFICACY AND SAFETY OF BI 655064, AN ANTAGONISTIC ANTI-CD40 ANTIBODY, IN PATIENTS WITH LUPUS NEPHRITIS}

D. Jayne ${ }^{1}$, J. Steffgen ${ }^{2}$, J. Romero-Diaz ${ }^{3}$, H. Amano ${ }^{4}$, K. Noppakun ${ }^{5}$, H. M. Gomez ${ }^{6}$, R. Recto ${ }^{7}$, V. Belsack ${ }^{8}$, N. Fagan ${ }^{9}$, S. Padula ${ }^{10}$, I. Revollo ${ }^{11}$, J. Wu ${ }^{12}, \mathrm{~S}$. Visvanathan ${ }^{13}$, R. Furie ${ }^{14} .{ }^{1}$ University of Cambridge, Department of Medicine, Cambridge, United Kingdom; ${ }^{2}$ Boehringer Ingelheim International $\mathrm{GmbH}, \mathrm{TA}$ Inflammation Medicine, Biberach, Germany; ${ }^{3}$ Instituto Nacional de Ciencias Médicas y Nutrición "Salvador Zubiran", Immunology and Rheumatology, Mexico City, Mexico; ${ }^{4}$ Juntendo University Hospital, Department of Medicine, Japan, Japan; ${ }^{5}$ Chiang Mai University, Thailand, Department of Internal Medicine, Chiang Mai, Thailand; ${ }^{6}$ Angeles University Foundation Medical Center, Rheumatology, Angeles City, Philippines; ${ }^{7}$ Mary Mediatrix Medical Center, Internal Medicine, Lipa City, Philippines; ${ }^{8}$ SCS Boehringer Ingelheim, Clinical Operations, Brussels, Belgium; ${ }^{9}$ Boehringer Ingelheim Pharmaceuticals Inc., Biostatistics \& Data Science, Ridgefield, United States of America; ${ }^{10}$ Boehringer Ingelheim International $\mathrm{GmbH}$, Ingelheim, TA Inflammation Medicine, Ingelheim, Germany; ${ }^{11}$ Boehringer Ingelheim International GmbH, Pharmacovigilance Corporate, Ingelheim, Germany; ${ }^{12}$ Boehringer Ingelheim Pharmaceuticals Inc., Translational Medicine and Clinical Pharmacology, Ridgefield, United States of America; ${ }^{13}$ Boehringer Ingelheim Pharmaceuticals Inc., Translational Medicine and Clinical Pharmacology, Ridgefield, United States of America; ${ }^{14}$ Northwell Health and Zucker School of Medicine at Hofstra/Northwell, Department of Rheumatology, Great Neck, United States of America

Background: In patients with SLE, activation of the CD40-CD40L pathway results in stimulation and proliferation of $B$ cells and other inflammatory cel types. The subsequent generation of autoantibodies and their deposition in the kidney, as well as activation of myeloid and resident kidney cells, result in local inflammation and eventually, kidney injury. Thus, CD40 is an appealing therapeutic target in lupus nephritis (LN). BI 655064 is a humanised anti-CD40 monoclonal antibody that blocks the CD40 pathway in a nanomolar range and downregulates activated $B$ cells.

Objectives: To assess the efficacy and safety over 52 weeks of three doses of subcutaneous $\mathrm{BI} 655064$ compared with placebo, as add-on to mycophenolate and steroids, in patients with active proliferative LN (ClinicalTrials.gov number: NCT02770170)

Methods: Overall, 121 patients with LN were randomised, double blind, in a 2:1:1:2 ratio to placebo or Bl $655064120 \mathrm{mg}, 180 \mathrm{mg}$ or $240 \mathrm{mg}$, and received a weekly loading dose for the first 3 weeks, followed by dosing every 2 weeks for the 120 and $180 \mathrm{mg}$ doses, and weekly $(120 \mathrm{mg})$ for the $240 \mathrm{mg}$ group. Key inclusion criteria included an active ISN/RPS class III or IV $( \pm \mathrm{V})$ renal biopsy within 3 months prior to screening and a screening protein/creatinine ratio of $\geq 1 \mathrm{mg} / \mathrm{mg}$. Randomisation was stratified based on race (Asian vs non-Asian) and screening protein/creatine (UP/UC) ratio ( $<3$ vs $\geq 3$ ). The primary efficacy endpoint was complete renal response (CRR), defined as $24 \mathrm{~h}$ proteinuria $<0.5 \mathrm{~g} /$ day and stable eGFR at Week 52.

Results: The placebo response in this trial was higher than expected (48.3\%; Table 1); none of the

BI 655064 doses increased rates of CRR at Week 52 compared with placebo. However, CRR at Week 52 based on creatinine-adjusted proteinuria, assessed using spot urine, showed a better response in the $180 \mathrm{mg}$ group $(50 \%)$ vs placebo (42.5\%), and the $180 \mathrm{mg}$ dose showed a greater change from baseline over 
time vs placebo from Week 4. Time to CRR was shorter in the $180 \mathrm{mg}$ group (17.3 weeks) vs placebo (20.4 weeks). The $180 \mathrm{mg}$ group also showed improvement vs placebo in total SLEDAI (SELENA) and its subscores.

The unexpected high placebo response prompted a post hoc analysis evaluating confirmed CRR (CCRR), whereby confirmation of the endpoint was required at both Weeks 46 (penultimate visit on treatment) and 52. A 15.2\% higher cCRR in the $180 \mathrm{mg}$ group $(44.3 \%)$ vs placebo $(29.1 \%)$ was observed $(p=0.26)$.

While based on a small sample size, there were more reports of infection-related severe and serious adverse events and neutropenia in the $240 \mathrm{mg}$ group compared with placebo. Of note, in those who experienced neutropenia, a clinical impact (e.g. increase in infections) was not established. Aside from these observations, safety data were comparable across treatment groups.

Larger decreases from baseline were observed in the percentage of CD27-lgD-CD95+, CD27-lgD+CD95+, CD27+lgD+CD95+ and CD27+lgD-CD95+ B-cell subsets in the 180 and $240 \mathrm{mg}$ groups compared with placebo.

Treatment-emergent anti-drug antibodies (ADAs) were detected in five patients treated with $\mathrm{BI} 655054$, all at low titre, and in one who received placebo; ADAs had no impact on pharmacokinetics or safety.

Conclusion: The trial did not meet its primary CRR endpoint. However, when confirmation of CRR was required at both Weeks 46 and 52, the resultant decrease in the placebo response generated an effect size of $15.2 \%$ and $9.1 \%$ in favour of $180 \mathrm{mg}$ and $240 \mathrm{mg} \mathrm{BI} 655064$, respectively.

Table 1. Efficacy endpoints at Week 52

\begin{tabular}{|c|c|c|c|c|}
\hline & \multirow[t]{2}{*}{ Placebo $(n=40)$} & \multicolumn{3}{|l|}{ BI 655064} \\
\hline & & $120 \mathrm{mg}(\mathrm{n}=21)$ & $180 \mathrm{mg}(\mathrm{n}=20)$ & $240 \mathrm{mg}(\mathrm{n}=40)$ \\
\hline Observed CRR, n & 20 & 8 & 9 & 18 \\
\hline Adjusted* CRR, \% & 48.3 & 38.3 & 45 & 44.6 \\
\hline Observed cCRR, $\mathrm{n}$ & 13 & 5 & 9 & 16 \\
\hline Adjusted $^{*}$ cCRR, $\%$ & 29.1 & 22.5 & 44.3 & 38.2 \\
\hline \multicolumn{5}{|c|}{ Mean change from baseline in SLEDAI } \\
\hline Total score & -6.5 & -6.1 & -9.7 & -8.2 \\
\hline Non-renal score & -1.4 & -3.0 & -2.8 & -3.1 \\
\hline Renal score & -5.1 & -3.7 & -6.8 & -5.0 \\
\hline Clinical score & -5.7 & -3.9 & -7.9 & -6.5 \\
\hline
\end{tabular}

CRR based on 24h proteinuria; cCRR based on UP/UC (spot urine) at Weeks 46 and 52 . *Logistic regression model including treatment and the covariates race and proteinuria at screening.

Disclosure of Interests: David Jayne Consultant of: DRJ has received consulting fees from AstraZeneca, Boehringer Ingelheim, GlaxoSmithKline Research \& Development Ltd, Novartis, and Roche, Juergen Steffgen Employee of: JS is employed by Boehringer Ingelheim., Juanita Romero-Diaz Consultant of: JRD has received research consulting fees from Boehringer Ingelheim, Hirofumi Amano Grant/research support from: HA has received research grants from Boehringer Ingelheim, Kajohnsak Noppakun Consultant of: KN has received honoraria from Boehringer Ingelheim, Novartis, Roche, Jansen, AstraZeneca, Otsuka Pharmaceuticals, Astellas Pharma, Abbott, Sanofi and Novo Nordisk, Grant/research support from: KN has received research grants from Boehringer Ingelheim, GlaxoSmithKline Research \& Development Ltd, Visterra Inc., Kalbe Genexine Biologics, Aurinia Pharmaceuticals Inc., and Omeros Corporation., Harold Michael Gomez Speakers bureau: HMG has received speaker's fees for Pfizer, MSD, Unilab, Astellas Pharma, AstraZeneca, GlaxoSmithKline Research \& Development Ltd, and Aurinia Pharmaceuticals Inc., Rhona Recto: None declared, Valérie Belsack Employee of: Boehringer Ingelheim, Nora Fagan Employee of: Boehringer Ingelheim, Steven Padula Employee of: Boehringer Ingelheim, Ivette Revollo Employee of: Boehringer Ingelheim, Jing Wu Employee of: Boehringer Ingelheim, Sudha Visvanathan Employee of: Boehringer Ingelheim, Richard Furie Consultant of: RF has received research consulting fees, Grant/research support from: RF has received clinical trial support DOI: 10.1136/annrheumdis-2021-eular.1401

\section{POS0688 CHARACTERIZATION OF PK/PD OF ANIFROLUMAB IN PATIENTS WITH MODERATE TO SEVERE SLE}

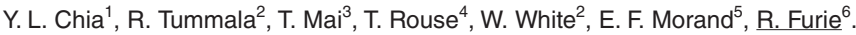
${ }^{1}$ AstraZeneca, BioPharmaceuticals R\&D, South San Francisco, United States of America; ${ }^{2}$ AstraZeneca, BioPharmaceuticals R\&D, Gaithersburg, United States of America; ${ }^{3}$ Genentech, Clinical Pharmacology and Modeling \& Simulation, South San Francisco, United States of America; ${ }^{4}$ AstraZeneca, BioPharmaceuticals R\&D, Gothenburg, Sweden; ${ }^{5}$ Monash University, Centre for Inflammatory Disease Monash Health, Melbourne, Australia; ${ }^{6}$ Zucker School of Medicine at Hofstra/Northwell, Division of Rheumatology, Great Neck, United States of America

Background: In the TULIP-1 and TULIP-2 trials, anifrolumab, a type I interferon (IFN) receptor antibody, at a dosage of $300 \mathrm{mg}$ once every 4 weeks (Q4W), demonstrated consistent median pharmacokinetic (PK) concentrations ${ }^{1}$ and sustained neutralization of the pharmacodynamic (PD) 21-gene type I IFN gene signature (IFNGS) $)^{2-4}$ in patients with moderate to severe systemic lupus erythematosus (SLE) despite standard therapy.

Objectives: To characterize the PK/PD relationship of anifrolumab and to confirm anifrolumab $300 \mathrm{mg}$ provides adequate PD neutralization in IFNGS testhigh patients.

Methods: This study included IFNGS test-high patients from the phase 3 randomized, placebo-controlled, 52-week TULIP-1 ${ }^{2}$ (NCT02446912) and TULIP-2 ${ }^{3}$ (NCT02446899) trials of intravenous anifrolumab $150 \mathrm{mg}$ or $300 \mathrm{mg}$ Q4W plus standard therapy. IFNGS test status (high or low) at screening was classified with an analytically validated 4-gene GPCR based test on whole blood. ${ }^{2}$ PD neutralization was measured with 21-gene type I IFNGS and expressed as a percentage change from baseline. ${ }^{3}$ For the graphic PK/PD analysis, patients with $\geq 1$ quantifiable serum PK sample and $\geq 1$ PD measurement before discontinuation were categorized depending on $\mathrm{C}_{\text {ave }}$ (individual predicted average anifrolumab concentration over treatment duration) median and tertiles $(T)$ for anifrolumab $150 \mathrm{mg}$ and $300 \mathrm{mg}$, respectively. Median PD IFNGS neutralization and medium absolute deviations were compared across $\mathrm{C}_{\text {ave }}$ subgroups. PK/PD modeling was assessed in patients with $\geq 1$ quantifiable serum PK sample and a baseline and $\geq 1$ postbaseline PD measurement before discontinuation, using a nonlinear mixed-effects model (NONMEM; version 7.3; ICON) to estimate parameters and characterize the PK/PD data. The PD/efficacy analysis included patients with $\geq 1$ postbaseline PD measurement before discontinuation. BILAG-based Combined Lupus Assessment (BICLA) response rates at Week (W)52 were compared across median PD neutralization quartiles $(\mathrm{Q})$ for pooled anifrolumab $300 \mathrm{mg}$ and $150 \mathrm{mg}$ groups.

Results: The PK/PD graphic analysis included 654 IFNGS test-high patients (placebo [ $\mathrm{n}=293]$; anifrolumab $150 \mathrm{mg}[\mathrm{n}=72]$ or $300 \mathrm{mg}[\mathrm{n}=289]$ ). $\mathrm{C}_{\text {eve }}$ was generally higher with anifrolumab $300 \mathrm{mg}(\mu \mathrm{g} / \mathrm{mL}$, TULIP-1: T1 $<32$, T2 32-<44.3, T3 $\geq 44.3$; TULIP-2: T1 <32.4, T2 32.4-<47.9, T3 $\geq 47.9$ ) than with anifrolumab $150 \mathrm{mg}$ (median $11.5 \mu \mathrm{g} / \mathrm{mL}$ ); overlap between anifrolumab $300 \mathrm{mg}$ and $150 \mathrm{mg} \mathrm{C}$ ave subgroups was small owing to nonlinearity. Anifrolumab $300 \mathrm{mg}$ elicited rapid

Figure. Observed PD neutralization of the 21-gene type I IFNGS according to $C_{\text {amo }}$ subgroup over the 52-week treatment duration in A) TULIP-1 and B) TULIP-2
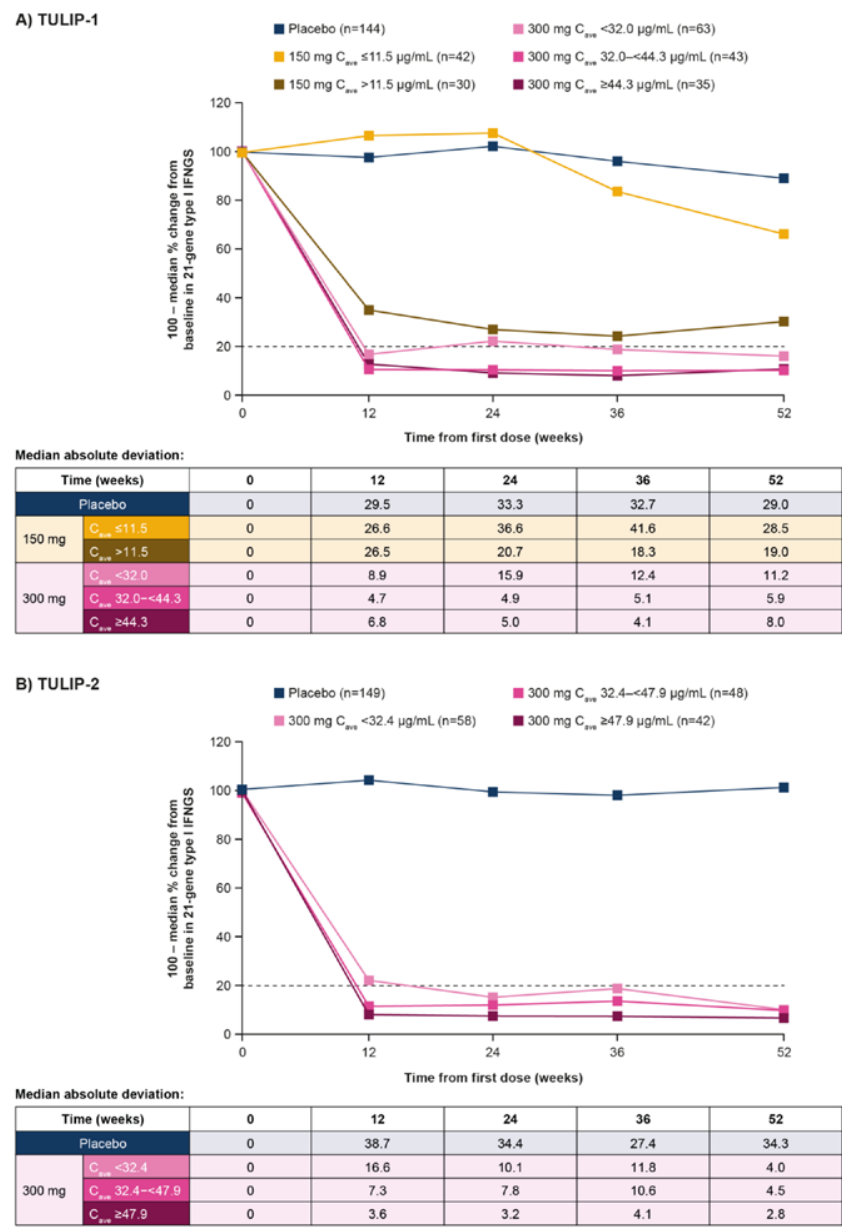

C..., average anifrolumab concentration over the treatment period; IFNGS, interferon gene signature; PD, pharmacodynam PK., pharmacokinetic. Figure includes patients with 21 quantifiable serum PK observation and 21 PD, measurement prior to discontinuation Po collected after discontinuations were not tincluded. 